International Journal of Language, Literature and Gender Studies (LALIGENS)

Ethiopia

Vol. 3 (2), Serial No 8, May, 2014:89-107

ISSN: 2225-8604(Print) ISSN 2227-5460 (Online)

http://dx.doi.org/10.4314/laligens.v3i2.6

\title{
ELEME NOUN INCORPORATION
}

\author{
NGULUBE, ISAAC EYI, Ph.D. \\ Department of English Studies \\ University of Port Harcourt \\ Port Harcourt, Rivers State, Nigeria \\ E-mail: isaaceyingulube@yahoo.com \\ Mobile: +2348075220804
}

\begin{abstract}
This paper generally argues that in Eleme the process of elision triggers a number of other phonological processes such as aphaeresis, apocope, syncope; it offers concrete evidence of tone stability in the face of segment deletion, and evidence of noun incorporation. More specifically, it argues that superficially, Eleme elision process appears to indicate that the noun following the verb is incorporated into the stem. In other words, in Eleme, prosodically independent elements following inflected verb stem frequently become phonologically integrated with the stem following elision of the syllable nucleus. Constructions of this type are clear instances of noun incorporation in the sense of Mithum (1984), Gerdts (1988), T. Mohanan (1994, 1995), Bresnan and Michombo (1995) and Bresnan (2001) since they exhibit all the grammatical properties of this
\end{abstract}


process. But, I caution that care should be exercised in analysing the relationship between a verb stem and following object as noun incorporation since incorporation in Eleme is often attributable to hiatus resolution strategies. This paper suspects that noun incorporation may actually exist in Eleme but the elision process discuss in it does not result into such constructions that admit the term noun incorporation.

\section{Introduction}

This introductory section accomplishes two things. It introduces the language under investigation and states the purpose of the study. Eleme is spoken in Eleme Local Government Area of Rivers State, in south-eastern Nigeria. The Eleme-speaking area, which covers approximately 140,000 square kilometres, lies between $4^{0} .35^{0}$ and $4^{0}$ $60^{0} \mathrm{~N}$, and $7^{0} 10^{\circ}$ and $7^{0} .15^{\circ} \mathrm{E}$. The Eleme territory neighbours several LGAs whose boundaries often reflect ethnic and/or linguistics groupings within the region. Baan, Tee (Tai), Gokana and Yeghe (Ngulube 2008) make up the Ogonoid group. Of recent Eleme is classified as: Niger-Congo; Benue-Congo; Cross River; Delta Cross; Ogonoid; Eleme (Bond et al., 2005).

An investigation of the concept of incorporation is of significant theoretical interest, as it will provide further insight into linguistic typologies and variations. It is a consensus that the inferences that can be made about the attributes of universal grammar depend on the attested characteristics of individual languages. From the known features of particular languages, we can abstract the universal properties that they share. The differences discerned in specific languages are vital for the development of an adequate explanatory linguistic theory. Ignorance of such differences will restrain the explanatory strength of existing theories (Isaac 2003:13). It is against this backdrop that the need to investigate Eleme noun incorporation derives its theoretical validity.

More specifically, this paper argues that in Eleme the process of elision triggers a number of other phonological processes such as 
aphaeresis, apocope, syncope; it offers concrete evidence of tone stability in the face of segment deletion; it tenders strong evidence of noun incorporations. It argues further that at a superficial level, Eleme elision processes appear to indicate that the noun following the verb is incorporated into the stem. But, it cautions that care should be exercised in analyzing the relationship between a verb stem and following object in Eleme as noun incorporation since incorporation in Eleme is often attributable to hiatus resolution strategies.

\section{History}

Before I turn to specific empirical cases, I would like to round out this introduction to noun incorporation with a brief, impressionistic view of its history, focusing on the Americas. Arguably linguistics in the Americas and elsewhere began as an extension of colonial activity, specifically missionary work. Everett (2005:5) reports that in Brazil, the French Calvinist Chronicler Jean de Lery (1534-1613), compiled fascinating and extremely useful records of Tupinambá conversations. Today this once widely spoken language lives as a communication system only in the conversation recorded by Lery. Contemporary with de Lery was the amazing Padre de Anchieta (1533-1597), founder of the city of Sao Paulo, co-founder of the city of Rio de Janeiro, and the author of a brilliant grammar of Tupinambá and translator of many catechisms into this language: Anchieta could plausibly be called the founder of linguistics in Americas. Following Anchieta was Padre Antonio Ruize de Montoya (1585-1652), who produce brilliant studies of the Guarani language. Montoya has what I believe to be the first insightful discussion of noun incorporation and possessor raising anywhere, offering a brilliant account of how the verb's case is freed up after noun incorporation to be re-assigned to the possessed NP over 300 years before, say, Mark Baker's (1988) theory of incorporation. This brief historical account of the origin of noun incorporation evinces that the phenomenon is by no means a new concept. Mark Baker's theory is at best a refinement of Montoya. But in this paper, I shall restrain myself to the formalization of IN in Mithun (1984). I now turn to elucidation of incorporation. 


\section{Incorporation}

Here, I shall present four definitions from three different sources; three of which are incorporated noun (IN) and one of which is pronoun incorporation (PI). I will follow this up with an examination of the empirical evidence from Greenlandic special class of suffixes. After which, I return to the discussion of IN in Eleme.

In a detailed study into the evolution of noun incorporation, Mithun proposes four stages in the diachronic development of this phenomenon. I shall consider only the first stage since; it is the aspect relevant to my argument here. The first stage, referred to as lexical compounding, is characterized by the formation of compounds with a more specific meaning than their composite parts:

The compound is more than a description; it is the name of an institutionalized activity or state. The IN [incorporated noun] loses its individual salience both semantically and syntactically. It is no longer refers to a specific entity; instead it simply narrows the scope of the $V$ (Mithun 1984:856).

Bresnan (2001:93) discussing lexical integrity suggests that the structural formation of words is independent of the structural formation of phrases. She cites Warlpiri c-structure were the relative order of words in sentences is extremely free while the relative order of stems and inflections in words (such as the case and tense markers) is fixed. She asserts that 'morphemic order' within words is rigidly encapsulated from the kind of scrambling and free orderings seen in word-external structures. Not only the order of word-internal elements but their structural types also differ from that of c-structure phrases.

Even in cases of word formation that appear to interact with the structure of the clause, such as West Greenlandic noun incorporation where a verbinternal noun stem may specify an f-structure complement of the clause, the incorporated noun is 
a bound stem, which lacks the structural properties of syntactic noun phrases (such as case morphology).

Bond (2006:74) in his study of Eleme verbal 'morphosyntax' postulates:

Noun incorporation is a morphological process in which a noun (usually a direct object) and a verb stem become compounded to yield a complex form that serves as the predicate for the entire clause. Incorporated nouns characteristically exhibit restricted nominal morphology.

Bresnan (2001:144) asserts that morphological words may determine the same kinds of functional structures as syntactic phrases. Although, she argues further that there is typological variation in the degree of functional specification provided by word structure versus phrase structure. She also suggests that in the grammars of some languages bound morphemes carry as much functional information as syntactic c-structure constituents. According to her:

A widespread typological phenomenon called pronoun incorporation or pronominal inflection...an incorporated pronoun is a bound morpheme that specifies a complete pronominal f-structure. The functional specification of a pronoun is incorporated with the functional specifications of the stem to which the morpheme is bound'.

A study of these references and others not cited here such as $\mathrm{T}$. Mohanan (1994, 1995), Bresnan and Mchombo (1995) reveal that the properties of the incorporated noun are:

(i) Noun incorporation is as a result of the morphological process of compounding. 
(ii) The resultant complex form from this process must serve as the predicate for the entire clause.

(iii) The incorporated noun characteristically exhibits restricted nominal morphology.

(iv) The incorporated noun is bound to the stem.

(v) It is devoid of the structural properties of the syntactic noun phrases, i.e. it cannot be assigned case, number and person.

(vi) It specifies a complete nominal f-structure.

In the course of this paper, I will examine these characteristics and use them to analyze the outcome of the Eleme elision process and showcase why these complex forms should or should not be regarded as noun incorporation. I now turn to the specific task of illustrating noun incorporation. All Greenlandic data is from Bresnan (2001). In Greenlandic a special class of suffixes: -qarpoq 'have' and -sivoq 'buy' fuse with nouns to generate verbs in which the incorporated noun functions as a syntactic argument of a verb encoded by the suffix. For instance, the nouns qimmeq 'dog' and sapangaq 'bead' are realized as derived verbs if they fuse with the verbal suffixes, see Ex. 1 below:

Ex. 1 (i) qimmeq

(ii) Qimmeq - qarpoq.

(iii) sapangap

(iv) Sapangar-sivoq. 'dog'

'He has a dog.'

'bead'

'He bought beads.'

In this language, Bresnan reports that NP specifiers and the NP they modify have the same case (see Ex. 2 below).

$E x .2$ (i) Anguti-p angisuu-p takuvaanga man-Erg big-Erg see: Indic. 3sg. 1. sg

The big man saw me. 
(ii) Angum - mik angisuu - mik tikippoq man - Inst big - Inst came: Indic. 3. sg He came with a big man.

In $E x$. (2i) the noun angutip and its modifier angisuup are both tagged ergative case. The same applies to Ex. (2ii) where the noun angummik and its specifier angisuumik are both tagged instrumental case. Now compare Ex. 2 above with Ex. 3 below where the incorporated syntactic arguments can similarly be specified, but the specifiers appear as distinct lexical items in the instrumental case.

Ex. 3

(i) Angisuu - mik qimmeq - qarpoq

big - Inst dog - have Indic. 3. sg

He has a big dog.

(ii) Kusanartu - mik sapangar - sivoq

beautiful - Inst bead - get. Indic. 3. sg

He bought a beautiful bead.

In Greenlandic there is a neutralization of the number of the incorporated noun in certain cases, whereas plurality is expressed via the choice of plural specifier. Compare Ex. 3 with Ex. 4.

Ex. 4

(i) Kusannartu - mik Sapangar - sivoq

Beautiful - Inst. PL bead - get Indic. 3. sg

He bought beautiful beads.

(ii) Ataatic - nik qamu teq-qarpoq

one - Inst. PL sled - have Indic. 3. sg

He has one sled. 
A typical plural noun such as qamutit 'sled' obligatorily selects plural form of the specifier, as in Ex. 4ii. In Ex. $1-E x$. 4, the incorporated nouns are bound to the stem; they lack the structural properties of the syntactic noun phrases; in these instances, they cannot distinguish number; although they share ergative and instrumental cases with their respective specifiers. In Ex. 3 and Ex. 4 the incorporated nouns specifies a complete nominal $\mathrm{f}$ - structure as sketched below.

argument (a-) structure: verb

functional (f-) structure:

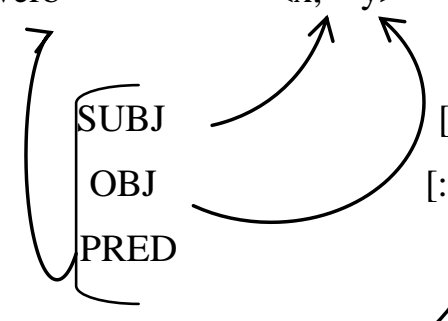

categorical (c-) structure:
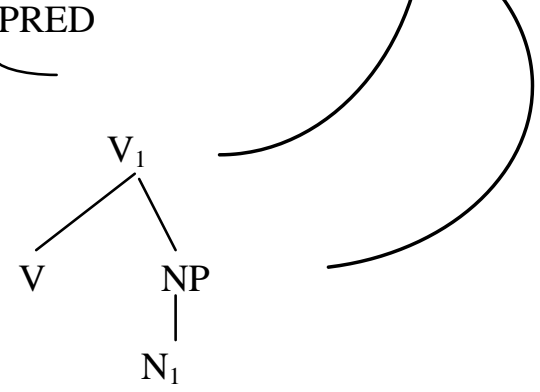

From the above data these c-structures and functional equations are derived:
$\mathrm{R} 1 \quad \mathrm{~S} \quad \rightarrow \quad(\mathrm{NP})$
(NP)
(NP)
V $(\uparrow \mathrm{SUBJ})=\downarrow$
$\mathrm{R} 2 \quad \mathrm{NP} \rightarrow \begin{array}{r}(\mathrm{N}) \\ \uparrow=\downarrow\end{array}$
$\uparrow \mathrm{OBJ})=\downarrow$
$(\uparrow \mathrm{OBL})=\downarrow \uparrow=\downarrow$
$(\mathrm{N})$
$(\uparrow \mathrm{ADJ})=\downarrow$
$(\uparrow \mathrm{CASE})=(\downarrow \mathrm{CASE})$ 


\section{Eleme Noun Incorporation}

auUve IUHUwilly DIesilall ( $\angle U U 1)$.

(L1) tikippoq

$\mathrm{V}:$

$$
\begin{array}{ll}
(\uparrow \mathrm{PRED})=\text { 'come }\langle(\uparrow \mathrm{SUBJ})\rangle \\
(\uparrow \mathrm{SUBJ}) \mathrm{NUM} & =\mathrm{SG} \\
(\uparrow \mathrm{SUBJ} \text { PERS }) & =3 \\
(\uparrow \mathrm{SUBJ} \text { CASE }) & =\mathrm{ABS}
\end{array}
$$

$$
\begin{aligned}
\text { (L2) takuvara } \quad \mathrm{V}: \quad(\uparrow \mathrm{PRED}) & =\text { see }\langle(\uparrow \mathrm{SUBJ})(\uparrow \mathrm{OBJ})\rangle, \\
(\uparrow \mathrm{SUBJ}) \mathrm{NUM} & =\mathrm{SG} \\
(\uparrow \mathrm{SUBJ} \text { CASE }) & =\mathrm{ERG} \\
(\uparrow \mathrm{SUBJ} \text { PERS }) & =1 \\
(\uparrow \text { OBJ CASE }) & =\mathrm{ABS} \\
(\uparrow \text { OBJ NUM }) & =\mathrm{SG} \\
(\uparrow \text { OBJ PERS }) & =3
\end{aligned}
$$$$
\text { (L3) -qarpoq } \quad \mathrm{V}:(\uparrow \text { PRED) } \quad=\text { 'have }<(\uparrow \mathrm{SUBJ})(\uparrow \mathrm{OBJ})
$$$$
\text { , }
$$

$$
\begin{aligned}
(\uparrow \mathrm{SUBJ}) \mathrm{NUM} & =\mathrm{SG} \\
(\uparrow \mathrm{SUBJ} C A S E) & =\mathrm{ERG} \\
(\uparrow \mathrm{SUBJ} P E R S) & =1 \\
(\uparrow \mathrm{OBJ} \text { CASE }) & =\mathrm{ABS} \\
(\uparrow \mathrm{OBJ} \text { NUM }) & =\mathrm{SG} \\
(\uparrow \mathrm{OBJ} \text { PERS }) & =3
\end{aligned}
$$

$$
\begin{aligned}
& \text { (L4) }- \text { sivoq } \quad \mathrm{V}:(\uparrow \mathrm{PRED}) \quad=\text { 'buy }<(\uparrow \mathrm{SUBJ})(\uparrow \mathrm{OBL}) \\
& (\uparrow \mathrm{SUBJ} \mathrm{CASE})=\mathrm{ABS} \\
& (\uparrow \mathrm{SUBJ} \text { NUM) }=\mathrm{SG}
\end{aligned}
$$




\section{$(\uparrow \mathrm{SUBJ}$ PERS $) \quad=1$ \\ $(\uparrow \mathrm{OBL}$ CASE) $=$ INST}

(L1) evinces an intransitive verb with a single argument; (L4) is equally an intransitive verb with double arguments, whereas (L2) and (L3) are transitive verbs whose objects are cross-referenced on the verb. A lexical form is a predicate argument structure associated with argument grammatical functions (Bresnan 2001:342). Secondly, the following 'sublexical v' c-structure rules for nouns in Greenlandic are exemplified below:

$$
\begin{array}{ccc}
\text { (RS1) } & \mathrm{N} \rightarrow \mathrm{N} \text { stem } & \mathrm{N}_{\mathrm{aff}} \\
& \uparrow=\downarrow & \uparrow=\downarrow \\
(\mathrm{RS} 2) \quad \mathrm{N} \rightarrow & \mathrm{N} \text { stem } \\
& \uparrow=\downarrow \\
& (\uparrow \mathrm{CASE})=\text { ABS }
\end{array}
$$

\begin{tabular}{|c|c|c|c|c|}
\hline L5 & qimmeq & $\mathrm{N}_{\text {stem }}$ & (个PRED) & $=$ 'dog' \\
\hline L6 & $-\mathrm{p}$ & $\mathrm{N}_{\mathrm{aff}}$ & $(\uparrow \mathrm{CASE})$ & $=\mathrm{ERG}$ \\
\hline \multirow[t]{2}{*}{ L7 } & - mik & $\mathrm{N}_{\mathrm{aff}}$ & $(\uparrow \mathrm{CASE})$ & $=\mathrm{INST}$ \\
\hline & & & ( $\uparrow N U M)$ & $=\mathrm{SG}$ \\
\hline \multirow[t]{2}{*}{ L8 } & - nik & $\mathrm{N}_{\mathrm{aff}}$ & $(\uparrow \mathrm{CASE})$ & $=\mathrm{INST}$ \\
\hline & & & ( $\uparrow N U M)$ & $=\mathrm{PL}$ \\
\hline L9 & sapangaq & $\mathrm{N}_{\text {stem }}$ & $(\uparrow P R E D)$ & $=$ 'bead' \\
\hline L10 & angisu & $\mathrm{N}_{\text {stem }}$ & $(\uparrow P R E D)$ & = ‘big' \\
\hline L11 & qamuteq & $\mathrm{N}_{\text {stem }}$ & (†PRED) & $=$ 'sled' \\
\hline
\end{tabular}$$
\uparrow=\downarrow
$$

The notion express here is that all nouns in Greenlandic have case, and that a noun, which is not marked for case by a case affix, bears the unmarked case, which is absolutive. The following sublexical entries are vital: 
Eleme Noun Incorporation

(IIVUivi) $-1 \mathrm{~L}$

The discussion sketched above shows that the concept under study is cross-linguistically attested. I now return to the Eleme situation, drawing on the presentation above.

\section{Elision}

The process of elision that occurs between a verb stem and its object in Eleme is a phenomenon that can be called noun incorporation. It seems that incorporation in Eleme is attributable to hiatus resolution strategies (Bond 2006). In Eleme, prosodically, independent elements following inflected verb stem frequently become phonologically integrated with the stem following elision of the syllable nucleus. Constructions of this type are clear instances of noun incorporation in the sense of Mithum (1984), Joan Gerdts (1988), T. Mohanan (1994, 1995), Bresnan and Michombo (1995) and Bresnsn (2001), since they exhibit all the grammatical properties of this process. In particular unstressed noun prefixes in word-initial positions are prone to elision (aphaeresis), especially following a verb stem. Elision of a vowel in word-final position (apocope) is also quite common in Eleme. The discussion here targets elision with regards to 'tone preservation' (Odden, 1995:446) and 'noun incorporation' (cf Mithum 1984:856).

\section{Tonal stability}

Tonal stability (popularly known as tonal preservation) is a situation whereby when a vowel is deleted the tone that it carries remains (Odden, 1995:446). Yip (2002:74) asserts that tonal stability is in fact the norm under segmental deletion in tonal languages. She observes:

Since tones are on a separate tier, and are associated to prosodic structure, there is no particular reason to expect them to be affected by segmental deletion rules. Tonal stability under deletion is thus the norm, and re-association will follow from other properties of the grammar.... 
In Eleme, this process can trigger tonal spread, coalescence or shortening depending on the context, tonal class and rule.

Consider the relevant examples from Eleme provided below.

Ex.1 (a) àmì ǹ-d̄̄ rũ̀ = ē - dèjè ǹdzá [careful speech]

1SG 1SG-LOC=APPL DEP-eat food

I am in the process of eating food.

(b) àmì ̀̀-d $\bar{\jmath}=\mathrm{r}$-é-dèjè ǹdzá [connected speech]

1SG 1SG-LOC=APPL DEP-eat food

$I$ am in the process of eating food.

In Ex. 1 and subsequent examples, note that first the hyphens are used to indicate morpheme boundaries. Second, the (a) examples are deliberate emphatic slow utterances in which the speakers select their words carefully so the effect is maximized. In contrast, the (b) examples are fast-connected utterances in which the speakers gloss over words quickly so the effect is minimized. In $E x .1 b$, the final high back nasalized vowel of the inflected stem $\grave{n} \quad-d \bar{\jmath}=$ rũ்- is deleted (elided) and the alveolar approximant [r] is resyllabified as the onset of a CV syllable [re]. The dependent - verb prefix of the following dependent -verb, e -, forms the nucleus of the syllable. This example suggests that Eleme does not permit vowel hiatus. It is this type of data that led Bond (2006) to posit that incorporation in Eleme is attributable to hiatus resolution strategies. But in Eleme hiatus occurs where two adjacent vowels belong to consecutive syllables without an intervening consonant, as in words kai 'dry', nia 'look' or the final and initial vowels of two successive words, as in the phrases dziete 'climb tree' and alo oku 'weave basket'. Hiatus is the opposite of elision, the dropping or blurring of the second vowel; it is distinct from 'diphthongization', in which the vowels blend to form one sound (Ladefoged and Maddieson 1996:303). Unlike Eleme, some languages do not permit hiatus and resort to vowel elision, epenthesis or coalescence, etc to resolve juxtaposed vowel sequences (Casali, 


\section{Eleme Noun Incorporation}

elided as evince in Ex. $1 \bar{b}$. This is an example of apocope in hiatus resolution. Apocope is the loss or omission of one or more syllables from the end of a word as in

A vital point to note here is that while the final vowel of $=$ rũ is deleted in Ex. $1 b$; the high tone that it otherwise bears (evident in Ex. la) above is preserved and realized on the vocalic prefix of the dependent verb. Eleme permits elision between a verb and its direct object. In Ex.2a, the inflected verb stem and following argument mbó 'goat' are prosodically distinct, whereas in Ex. $2 b$, the initial syllabic nasal of mbó 'goat' is deleted. This time the low tone of the syllabic nasal of the object argument is preserved under deletion and this is realized, along with nasalization, on the final vowel of the inflected verb stem. The construction in Ex. $2 b$ therefore exhibits aphaeresis (the loss of a syllable from the beginning of a word).
Ex.2 (a)
à?ò kú-ma m̀bó
(b) à?ò kú ma -ìbó
2SG herd - HAB goat
You herd goat.
2SG herd - HAB goat
You herd goat.

\section{Noun incorporation}

A similar pattern of elision is evident between certain verb stems and their cognate objects. In such cases, it is difficult to tell which of the vowel $\mathrm{V}_{1}$ or $\mathrm{V}_{2}$ got deleted; this is because the vowels share similar features. This is reflected in the interlinear gloss in the second of these examples, which does not represent a commitment to either analysis. The inflected stem precedes the object in these examples. Very often in situations like these some linguists posit contraction or reduction to account for the overt single vowel but there is no justifiable motivation for such analysis (cf Donwa-Ifode, 1985 for detail argument).
Ex. 3 (a) ว̀-dzว́ ว̀dz̄o
(b) j̀-dzó dz̧̄
2-swim swim
2-swim swim 


\section{You (SG) swam (a swim) You (SG) swam (a swim)}

Note that when the final vowel of the stem and the initial vowel of the cognate object do not share the same phonological properties, the vowel of the stem is elided, as in $(E x .4 b)$. Elision of the first vowel of the object is not permitted, as evinced in $(E x .4 c)$. This suggests that the vowel of the verb stem undergoes elision in constructions like ( $E x$. $3 b)$.

Ex. 4
(a) è-bé òbé
(b) è-b- òbé
(c) * è-bébē

3-fight fight

3-fight fight

3-fight fight

He fought (a fight).

He fought (a fight).

Bond (2006:74) posits that at a superficial level, the examples in $(1 b)$, $(2 b)$ and $(3 b)$ appears to indicate that the noun following the verb is incorporated into the stem. He explains noun incorporation thus:

Noun incorporation is a morphological process in which a noun (usually a direct object) and a verb stem become compounded to yield to complex form that serves as the predicate for the entire clause. Incorporated nouns characteristically exhibit restricted nominal morphology.

He follows this elucidation up by arguing that 'caution should be exercised in analyzing the relationship between a verb stem and the following object in Eleme as noun incorporation since incorporation in Eleme is often attributable to hiatus resolution strategies' (2006:75). In a detailed study into the evolution of noun incorporation, Mithum (1984) proposes four stages in the diachronic development of this phenomenon. The first stage, referred to as lexical compounding, is characterized by the formation of compounds with a more specific meaning than their composite parts: 


\section{Eleme Noun Incorporation}

[incorporated noun] loses its individual salience both semantically and syntactically. It no longer refers to a specific entity; instead it simply narrows the scope of the V (Mithun 1984: 856).

The examples in Exs (2b) and (3b) tally with this claim since the concepts expressed by the combined verb and noun in these constructions are recognizable, name-worthy activities (Mithun 1984: 848-9). In this instance, Bond is absolutely correct. Moreover, he argues that many of the traits of the lexical compounding stage of noun incorporation are not evident in the Eleme examples presented in the preceding discussion. For instance, it is unclear whether any difference in meaning exists between the examples in $(2 a)$ and $(3 a)$ and those in $(2 b)$ and $(3 b)$ respectively. Furthermore, Bond insists that there is paucity of nominal morphology in Eleme, although residue prefixes from a former noun class system remains. For this reason it is difficult to illustrate a reduction in the grammatical behaviour of objects that superficially appear to be incorporated. Besides, according to him, there is no morphological evidence that he is aware of to suggest that the verb stem and noun are treated as a unit, and he provides some evidences to suggest that they are not. In order to clarify his claim, he proffers the following examples in (5).

Ex. 5

(a) غ̀-dzó-rī j̀dzō

3-swim -3PL swim

They swam (a swim) (b) غ̀-dzó-r- j̀dz̄

3-swim -3PL swim

They swam (a swim)

Ex. 6
(a) è-dzé-ri èdzē
(b) è-dzé-r- èdzē
(c) *è-dzèdzērī 
3-dance-3PL dance 3-dance -3PL dance 3-dance -3PL dance They dance (a dance). They dance (a dance).

Ex. 7

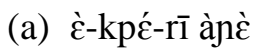
(b) * ̀े-kṕ́-r- ànغ̀
3-say: PTM-3PL 3SG
3-say: PTM-3PL 3SG
They said it to him.

Ex.8
(a) $\dot{\varepsilon}$-tã́mã́-rī-mī
(b) غ̀-tã́mã́-rī-m-àmì
3-shoot: PTM-3PL-01SG
3-shoot: PTM-3PL-01SG-1SG
They shot me (SG).
They shot ME.

Ex.9

(a) غ̀-tấmã́-rī-r-à?ò

(b) غ̀-tã́mã́-rī-b-àbà

3-shoot: PTM-3PL-02SG-2SG 3-shoot:PTM-3PL-03SG-3SG

They shot you (SG).

They shot THEM.

Ex.10

(a) غ̀-lấmã́-rī-i-ebāi

(b) غ̀-lấmã́-rī-i-obao

3-tell: PTM-3PL-03PL

3-tell-3PL-02SG-2PL

They told us.

They told you.

For Bond, these constructions show that the third-person plural subject suffix - rī, which normally attaches to the lexical verb stem, as in (Ex. $5 a$ ), or sometimes an auxiliary, continues to occupy this position when a following object is seemingly incorporated, as in $(E x .5 b)$. The ungrammatical construction $(E x .5 c)$ indicates that for the purposes of participant reference markings, the verb and following object are not treated as a unit. Other verbal suffixes exhibit similar behaviour, such as the habitual suffix in (Ex. 2). These examples show that for the 


\section{Eleme Noun Incorporation}

distinct. So, for him noun incorporation in Eleme is suspect.

Be that as it may be. My stand is clear. Compounding is a morphological process that integrates the NP object and the verb stem into a compound word use as the predication for the mega clause. These compounded words evince trait of a limited morphology (Mithun 1984, Gerdts 1998). In trying to explain what happens between the verb and its object in Eleme as IN circumspection is advised because incorporation in Eleme is as a result of resolving hiatus.

As example (Ex.2b) and (Ex.4b) show, Mithun's (1984:848-9) assertion is correct. The integrated noun and verb are observed but the other characteristics of the compounding are missing in the cited examples. For instance, there is no disparity in meaning between (Ex.2a / Ex.3a) and (Ex.26b/Ex3b) respectively. Secondly, the verb stem and noun are never considered as a unit (see examples (Ex.6) (Ex.7). The ri suffix is affixed to the verb (Ex.7) never to the integrated object $(E x .6 c)$. The ungrammaticality of (Ex.6c) shows that the verb stem + object are not considered as a unit especially in participant reference marking. These data suggest that in the morphological process of affixation stems + objects are disparate. Thirdly, another argument against noun incorporation is that the same phonological processes happen if NP + verb have the same referent. In example $(E x .8 a)$ the integrated noun is the non-emphatic -mi but in $(E x .8 b)$ the emphatic ami is used as the integrated noun. The suffix -i of the object is deleted while the a of ami is resyllabified as the nucleus of the first $\mathrm{CV}$ structure. This situation is also observed with the 2SG and 3PL emphatic objects as in (Ex.9).

Syntactically, nothing justifies this behaviour across disparate persons and numbers. Phonologically, this can be explained, the person/number contrast has bound object marker with -CV structure $m i(E x .8 a), r u(E x .9 a)$ and ba $(E x .9 b)$. Although in $(E x .8 b)$ and (Ex.9) the -u and -a are deleted and the object is phonologically 
merged, semantically and syntactically the object is not incorporated into the stem. This is an evidence of phonologic and syntactic mismatch, a phonological integration devoid of semantic and functional incorporation. As example (Ex.10) reveals, with 1PL and 2PL objects, the suffix -i form CVV in contrast to CV in others. Vowel deletion is blocked prohibiting integration into the stem. Observe (Ex.7a) which ends in CV yet no elision, the fact is that the bound object in $(E x .7 a)$ is not apparently marked, this is why the pronoun does not form a prosodic unit, forbidding (Ex.7b). In sum, I suspect that noun incorporation may actually exist in Eleme but the elision process discuss so far does not result into such constructions that admit the term noun incorporation.

\section{References}

Bond, Oliver \& Anderson, Gregory D. S. (2005). Divergent Structure in Ogonoid languages. Paper presented at 31st Annual Meeting of the Berkeley Linguistics Society, Berkeley, CA.

Bond, Oliver (2006a). A broader perspective on point of view: logophoricity in Ogonoid languages. In Selected Proceedings of the $35^{\text {th }}$ Annual Conference on African Linguistics: African Languages and Linguistics in Broad Perspectives, eds. John Mugane, John P. Hutchinson and Dee A. Worman, 234-244. Somerville, MA: Cascadila Proceeding Project.

Bond, Oliver (2006b). Aspects of Eleme verbal morphosyntax. Ph.D. thesis: University of Manchester.

Bresnan, Joan (ed.) (1982a). The mental representation of grammatical relations. Cambridge, Massachusetts: MIT Press.

Bresnan, Joan (2001). Lexical-functional syntax. Oxford, UK: Blackwell Publishing: 


\section{Eleme Noun Incorporation}

agreement in Chichewa, Language 03: 141-68'2.

Casali, Rod (1997). Vowel elision in hiatus contexts: which vowel goes? Language 73:493-308.

Donwa-Ifode, S.O. (1985). Glide formation, Assimilation and Contraction: A reassessment evidence from Isoko. Journal of West African Languages: XV 2, 41-55. 44:103-16

Everett, Daniel (2005). Coherent fieldwork. Piet van Sterkenberg, ed., Linguistics Today, John Benjamins.

Gerdts, Donna B. (1998). Incorporation. In Andrew Spencer and Arnold M. (eds.). The handbook of morphology, pp. 84-100. Zwicky, Oxford: Blackwells.

Isaac, Baridisi Hope (2003). Studies in Gokana Grammar, Ph.D. thesis: University of Port Harcourt, Nigeria.

Ladefoged, Peter \& Ian Maddieson (1996). The sounds of the world's languages. Oxford: Blackwell Publishing.

Mithun, Marianne (1984). The evolution of noun incorporation. Language 60: 847-894.

Ngulube, Isaac E. (2008). The phonology of Eleme. Ph.D. thesis: University of Manchester.

Odden, David (1995). Tone: African languages. In John A Goldsmith (ed). The handbook of phonological theory, Pp.444-475. Oxford: Blackwell.

Williamson, Kay (2004). Proto-Ijoid reconstructions. Version 2.0 [online]. Available

Yip, Mora (2002). Tone. Cambridge: Cambridge University Press.

Yul-Ifode, S. O. (1999). A Course in phonology with an Appendix on: Williamson's distinctive features. Riverside Communications, P. O. Box 7390, Federal Secretariat, Port Harcourt, Nigeria. 